Case Report

\title{
Heterotopic Ossification of the Peroneus Longus Tendon in the Retromalleolar Portion with the Peroneus Quartus Muscle: A Case Report
}

\author{
Song Ho Chang $(\mathbb{D}$, Takumi Matsumoto $\mathbb{D}$, Koichi Okajima, Masashi Naito, Jun Hirose, \\ and Sakae Tanaka iD \\ Department of Orthopaedic Surgery, Faculty of Medicine, The University of Tokyo, 7-3-1 Hongo, Bunkyo-ku, Tokyo 113-8655, Japan \\ Correspondence should be addressed to Song Ho Chang; s5chang@yahoo.co.jp
}

Received 21 March 2018; Revised 11 June 2018; Accepted 4 July 2018; Published 29 July 2018

Academic Editor: Paul E. Di Cesare

Copyright $(2018$ Song Ho Chang et al. This is an open access article distributed under the Creative Commons Attribution License, which permits unrestricted use, distribution, and reproduction in any medium, provided the original work is properly cited.

Heterotopic ossification (HO) is an ectopic formation of the lamellar bone in the soft tissues. Some authors have previously reported $\mathrm{HO}$ or calcific tendinitis of the peroneus longus tendon at the level of the cuboid bone, while the HO of the peroneus longus tendon in the retromalleolar portion has not been reported. The purpose of this report is to describe clinical, radiological, and histological features of this rare ossification and its treatment. To the best of our knowledge, this is the first report presenting a case of $\mathrm{HO}$ of the peroneus longus tendon, which developed in the retromalleolar portion.

\section{Introduction}

Heterotopic ossification (HO) is a pathologic condition in which the ectopic lamellar bone forms within the tendon, muscle, or other soft tissues. The etiology of $\mathrm{HO}$ has been classified into three groups: traumatic, neurologic, and genetic [1]. HO commonly involves the ankle joint. $\mathrm{HO}$ of the Achilles tendon has been typically reported by some authors [2]. Conversely, $\mathrm{HO}$ of the peroneus longus tendon is a relatively rare entity. A previous report referring to ossification or calcification of the peroneus longus tendon has focused and reported on lesions beneath the plantar aspect of the cuboid, lateral to the calcaneus, or at the level of the calcaneocuboid joint [3]. To the best of our knowledge, this is the first report to describe a case of $\mathrm{HO}$ of the peroneus longus tendon in the retromalleolar portion successfully resolved through surgical removal.

\section{Case Presentation}

A 50-year-old Japanese man visited a nearby orthopedic clinic complaining of persistent pain during ambulation and solid mass in his lateral retromalleolar portion, which had gradually grown since 5 years prior to visiting our hospital. Conservative treatment, including immobilization using an ankle brace and administration of NSAIDs, failed to reduce his persistent pain, and the patient was then referred to our hospital for surgical treatment. He had a medical history of severe left ankle sprain 35 years prior, which was treated with only bandage application. He was also diagnosed with rheumatoid arthritis 5 years prior at a nearby hospital, which was not treated with antirheumatic drugs. On the first visit to our hospital, his blood test showed the following results: CRP, $0.67 \mathrm{mg} / \mathrm{L} ; \mathrm{RF}$, $394 \mathrm{IU} / \mathrm{mL}$; MMP-3, $138 \mathrm{ng} / \mathrm{mL}$; and anti-CCP, $363 \mathrm{U} / \mathrm{mL}$. Physical examination revealed a solid mass sized $1 \times 5 \mathrm{~cm}$ over the retromalleolar portion of the left ankle along the course of the peroneal tendons (Figure 1). He had tenderness and slight swelling on the left retromalleolar space, but no local heat or redness. He had no joint swelling and pain other than the swelling on the left lateral retromalleolar area. Pain was elicited by active plantar flexion of the ankle and eversion of the foot. The range of motion of his left ankle was $5^{\circ}$ of dorsiflexion and $35^{\circ}$ of plantar flexion, which was limited compared with $10^{\circ}$ of dorsiflexion and $45^{\circ}$ of plantar flexion of his 


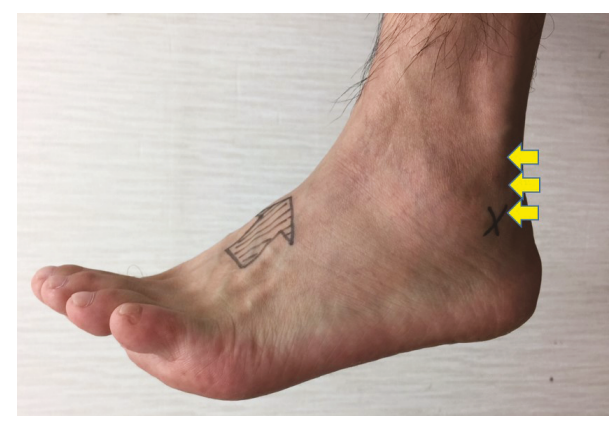

Figure 1: A solid mass $1 \times 5 \mathrm{~cm}$ in size was palpable over the retromalleolar portion of the left ankle along the course of the peroneal tendons (yellow arrows).

right ankle with his knees flexed. He had no instability in his ankle joint on the manual anterior drawer test.

$\mathrm{X}$-ray and CT showed a $1 \times 5 \mathrm{~cm}$ elliptical opacification along the course of the peroneal tendon from the level of the ankle joint at its distal end (Figure 2). Sagittal T1- and T2-weighted MR images showed an elliptical mass of a low intensity partially with high intensity with no contrast effect. Axial T1-weighted MR images showed a low-intensity mass in the peroneal tendon sheath, which seemed to compress both the peroneal brevis and longus tendons (Figure 3). Ultrasonographic image showed an elliptical mass with an echoic shadow on the affected side of the peroneal tendon sheath (Figure 4). We assumed that the mechanism of the present symptom was due to $\mathrm{HO}$ or calcinosis in the peroneal tendon sheath. Because of intractable pain and inability to walk, he hoped for a surgical treatment.

Surgery was performed through the retromalleolar curvilinear approach with a longitudinal $9 \mathrm{~cm}$ skin incision. The superior peroneal retinaculum and peroneal tendon sheath were incised. Longitudinal incision of the peroneus longus tendon revealed that the mass existed inside the peroneus longus tendon and its distal end was connected to the peroneus longus tendon (Figure 5). We excised the solid mass and a part of the peroneus longus tendon because no viable tendon remained in this part. The peroneus brevis tendon was intact, without any pathologic features. Because of the large defect after retraction of the peroneus longus tendon, an end-to-side transfer of the peroneus longus tendon to the peroneus brevis tendon was performed distally and proximally using monocryl sutures. We found a peroneus quartus muscle running along the peroneus longus tendon and subsequently excised it (Figure 5). The wound was irrigated and closed, and a sterile dressing was applied.

Microscopic examination revealed a lamellar bone formation with mixed tissue of fat and necrotic muscle. Calcification and cartilage metaplasia existed in the transitional zone between the ossification and the remaining tendon, that is, endochondral ossification (Figure 6). The pathological findings did not indicate intramembranous ossification. The histological diagnosis was $\mathrm{HO}$ of the peroneus longus tendon. A below-knee cast was applied on the patient in the operating room; instructions to maintain nonweight bearing for 3 weeks were also provided. After 3 weeks, full-weight bearing was allowed. The cast was removed 6 weeks postoperatively. The postoperative course was uneventful, and the patient returned to normal activities without any kind of functional disability. He started taking antirheumatic drugs at a nearby hospital 2 months after the surgery. We compared the outcomes of the surgery, using an objective standard rating system, the Japanese Society for Surgery of the Foot (JSSF) scale [4, 5], and the Self-Administered Foot Evaluation Questionnaire (SAFE-Q) [6]. The SAFE-Q is an ankle-specific subjective evaluation method consisting of 6 subcategories (i.e., pain and pain-related, physical functioning and daily living, social functioning, shoe-related, general health and well-being, and sports activity [optional]). The preoperative JSSF scale of 54 points (maximum score, 100 points) significantly improved to 100 points after 1 year. Compared to the preoperative condition, all subscale scores in the SAFE-Q improved after 1 year: pain and pain-related, 21 to 100 points; physical functioning and daily living, 50 to 86 points; social functioning, 21 to 88 points; shoe-related 100 to 100 points; and general health and well-being, 25 to 85 points.

\section{Discussion}

$\mathrm{HO}$ is defined as the formation of the lamellar bone in the soft tissues, such as the muscle and the joint capsule. Histologic examination of previous reports implicated that $\mathrm{HO}$ can be induced by both endochondral ossification and intramembranous ossification [2, 7]. HO occurs twice as frequently in male with no age predilection [8]. It occurs in a variety of conditions, such as previous trauma (tendon rupture or repeated microtrauma) [9], postarthroplasties [10], vasculopathies, central nervous system injury [11], burn injury [12], metabolic conditions, such as diabetes, Wilson's disease and ochronosis, DISH (diffuse idiopathic skeletal hyperostosis), and seronegative arthropathies [13]. In addition, genetic disorders, such as fibrodysplasia ossificans progressiva and progressive osseous heteroplasia, produce multiple $\mathrm{HO}$ lesions.

Recent studies have demonstrated that some molecular factors, such as the BMP family, HIFla, and scleraxis, have a key role in inducing ectopic bone formation [7, 14]; however, several issues remain to be elucidated. It has been suggested that three conditions are required for the formation of HO: [1] presence of an osteoinductive factor, [2] chondrocyte progenitor and osteoblast progenitor cells, and [3] environment permissive to osteogenesis [15]. Under these conditions, mesenchymal cells differentiate into chondrocytes or osteoblasts, which induce HO formation [16].

There is generally no standard treatment for HO. It has been suggested that NSAIDs, localized low-dose irradiation, retinoids, BMP inhibitors, and antagonists have some effect on the prophylaxis of $\mathrm{HO}$ formation [7]. These options are effective in preventing $\mathrm{HO}$; however, their efficacy is limited after fibroproliferation and cartilage formation. Surgical resection is the only treatment option to date once bone tissue formation is completed [7].

$\mathrm{HO}$ of the peroneal tendon is rare. One report focused on $\mathrm{HO}$ of the peroneus brevis tendon in a pediatric patient [17]. 


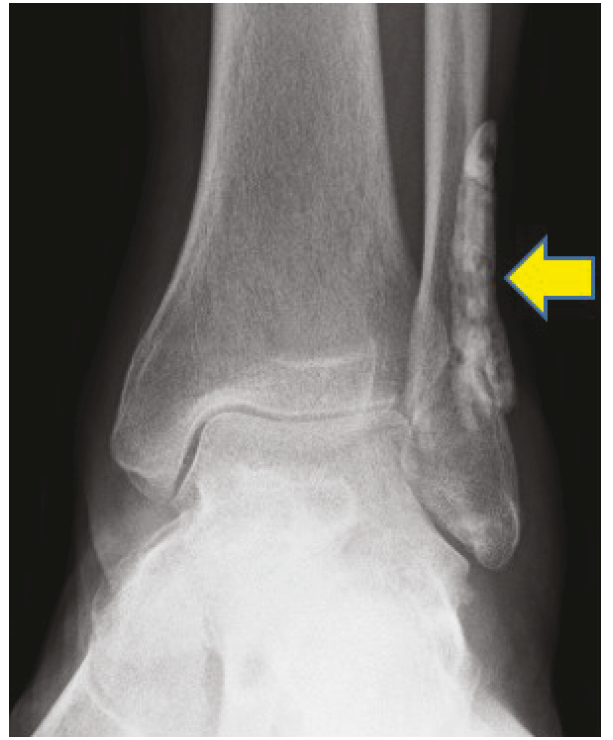

(a)



(b)

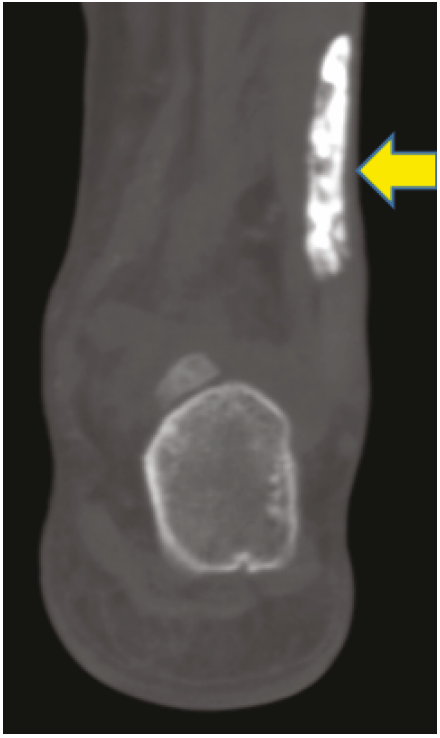

(c)

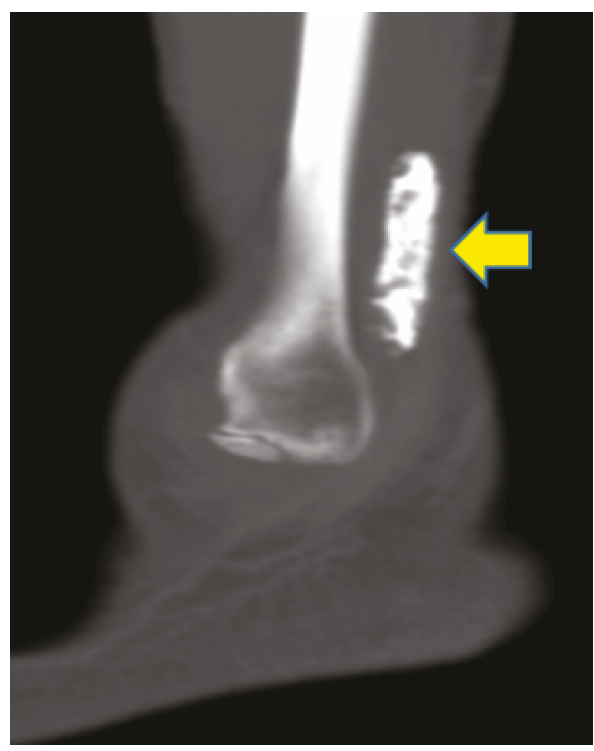

(d)

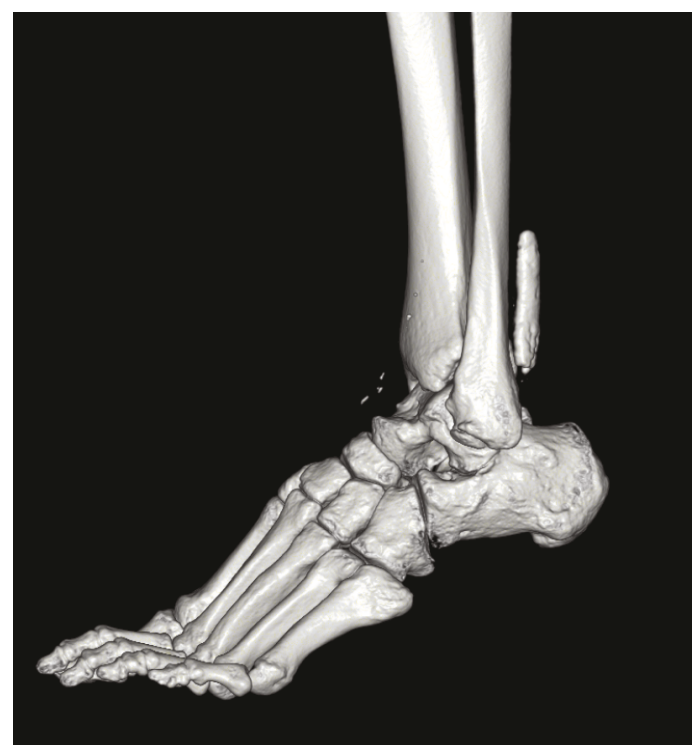

(e)

Figure 2: X-ray and CT showed a $1 \times 5 \mathrm{~cm}$ elliptical opacification (yellow arrow) along the course of the peroneal tendon. (a) AP view of the X-ray image. (b) Lateral view of the X-ray image. (c) Coronal section of the CT image. (d) Axial section of the CT image. (e) 3D reconstruction of the CT image.

Some cases of peroneus longus calcification have been reported [3, 18]; however, all reports revealed calcification of the peroneus longus tendon at the cuboid level. To the best of our knowledge, this is the first report to describe a case of $\mathrm{HO}$ of the peroneus longus tendon in the retromalleolar portion.

We found the peroneus quartus muscle running along the peroneus longus tendon in the present case. The peroneus quartus muscle is the most frequent supernumerary muscle around the foot and ankle. A few cases of chronic ankle pain, peroneal tendon sprains, or ankle instability caused by supernumerary muscle were reported. Surgical excision is a favorable treatment option for the symptomatic peroneus quartus muscle [19].
Inflammation following trauma is said to be the first step in the initiation of $\mathrm{HO}$ formation [20]. We assume that the triggering factor in the $\mathrm{HO}$ formation in the present case could be the severe ankle sprain experienced years prior, and the existence of the peroneus quartus muscle might have helped exacerbate the injury in the peroneus longus tendon. Furthermore, chronic inflammation might be maintained by the uncontrolled rheumatoid arthritis in this case.

In conclusion, we experienced the case of a patient with $\mathrm{HO}$ of the peroneus longus tendon in the retromalleolar portion with the peroneus quartus muscle. The present case was successfully treated with surgical removal of $\mathrm{HO}$ and the peroneus quartus muscle, together with peroneus longus transfer to the peroneus brevis tendon. 


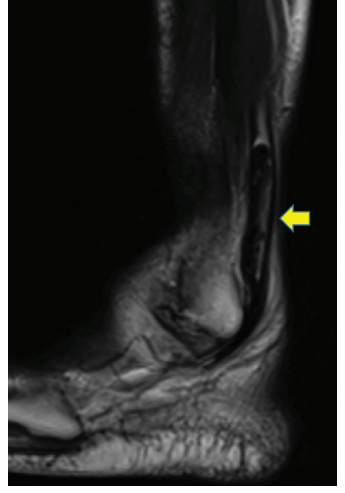

(a)

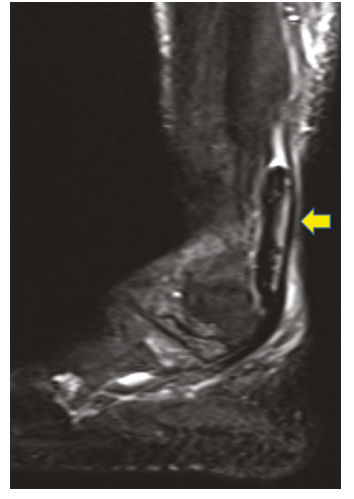

(b)

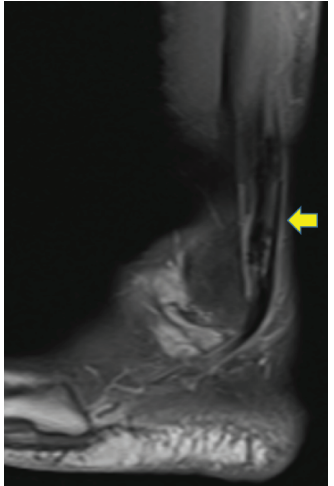

(c)

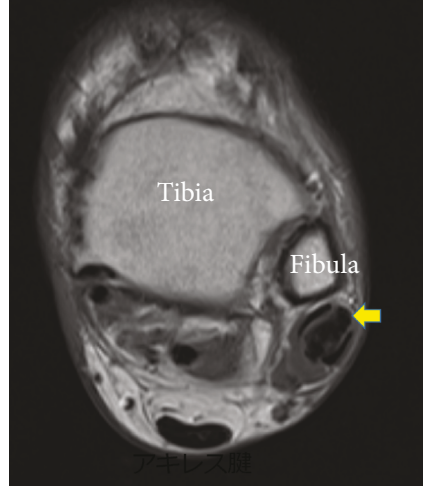

(d)

Figure 3: Sagittal T1- and T2-weighted MR images showed an elliptical mass of low intensity partially with high intensity with no contrast effect. Axial T1-weighted MR images showed a low-intensity mass (yellow arrow) in the peroneal tendon sheath, which seemed to compress both the peroneal brevis and longus tendons. (a) Sagittal T1-weighted image. (b) Sagittal T2-weighted image. (c) Sagittal enhanced image. (d) Axial T1-weighted image.

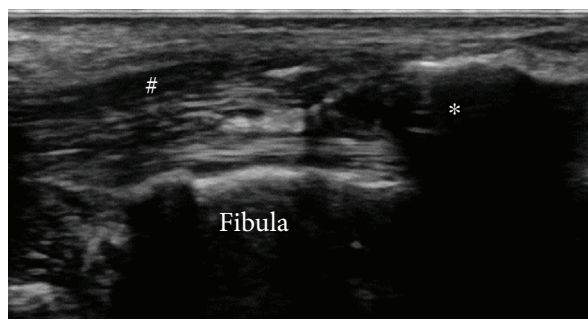

(a)



(b)

FIgURE 4: Ultrasonographic images showed an elliptical mass with an echoic shadow on the affected side of the peroneal tendon sheath. (a) Longitudinal image and (b) transverse image. ${ }^{*}$ Heterotopic ossification. ${ }^{\#}$ Peroneus longus tendon. ${ }^{\star}$ Peroneus brevis tendon.

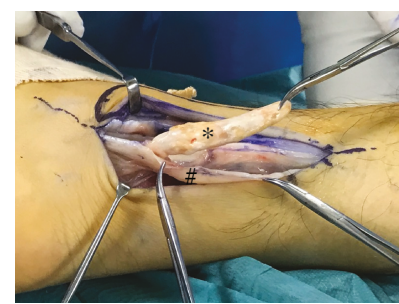

(a)

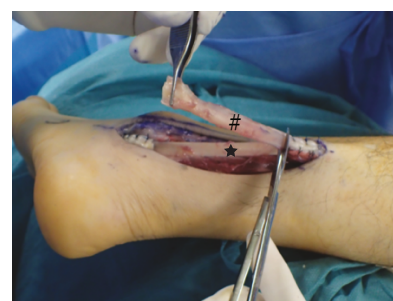

(c)

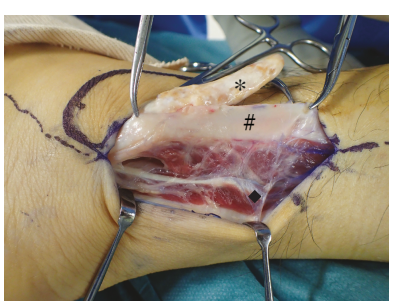

(b)

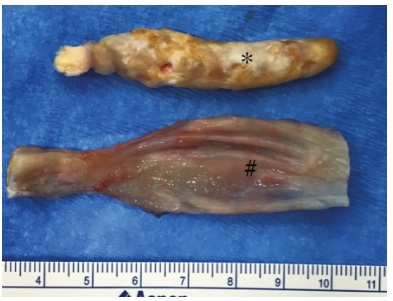

(d)

Figure 5: Resection of heterotopic ossification of the peroneus longus and peroneus quartus muscle. (a) Heterotopic ossification existed inside the peroneus longus tendon. (b) The peroneus quartus muscle running along the peroneus longus tendon was excised. (c) An endto-side transfer of the peroneus longus tendon to the peroneus brevis tendon was performed. The degenerated part of the peroneus tendon was excised. (d) Resected heterotopic ossification and degenerated part of the peroneus longus tendon. *Heterotopic ossification. ${ }^{\#}$ Peroneus longus tendon. ${ }^{\star}$ Peroneus quartus muscle. ${ }^{\star}$ Peroneus brevis tendon. 


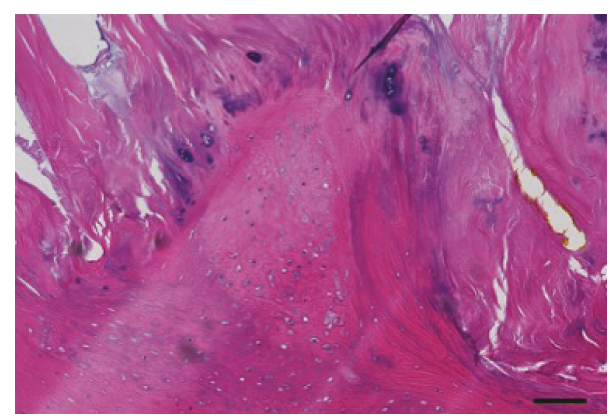

FIGURE 6: Microphotograph of the resected heterotopic ossification. Lamellar bone formation with an extensive cartilage metaplasia partly with mixed tissue of fat and necrotic muscle. Calcification and cartilage metaplasia existed in the transitional zone between the ossification and the remaining tendon, that is, endochondral ossification. Scale bar, $100 \mu \mathrm{m}$.

\section{Conflicts of Interest}

The authors declare that there is no conflict of interests regarding the publication of this paper.

\section{References}

[1] G. Grenier, E. Leblanc, N. Faucheux, D. Lauzier, P. Kloen, and R. C. Hamdy, "BMP-9 expression in human traumatic heterotopic ossification: a case report," Skeletal Muscle, vol. 3, no. 1, p. 29, 2013.

[2] M. Hatori, M. Matsuda, and S. Kokubun, "Ossification of Achilles tendon - report of three cases," Archives of Orthopaedic and Trauma Surgery, vol. 122, no. 7, pp. 414-417, 2002.

[3] D. Cox and F. W. Paterson, "Acute calcific tendinitis of peroneus longus," The Journal of Bone and Joint Surgery, vol. 73-B, no. 2, p. 342, 1991.

[4] H. Niki, H. Aoki, S. Inokuchi et al., "Development reliability of a standard rating system for outcome measurement of foot ankle disorders I: development of standard rating system," Journal of Orthopaedic Science, vol. 10, no. 5, pp. 457-465, 2005.

[5] H. Niki, H. Aoki, S. Inokuchi et al., "Development and reliability of a standard rating system for outcome measurement of foot and ankle disorders II: interclinician andintraclinician reliability and validity of the newly established standard rating scales and Japanese Orthopaedic Association rating scale," Journal of Orthopaedic Science, vol. 10, no. 5, pp. 466-474, 2005.

[6] H. Niki, S. Tatsunami, N. Haraguchi et al., "Validity and reliability of a self-administered foot evaluation questionnaire (SAFE-Q)," Journal of Orthopaedic Science, vol. 18, no. 2, pp. 298-320, 2013.

[7] K. Shimono, K. Uchibe, T. Kuboki, and M. Iwamoto, "The pathophysiology of heterotopic ossification: current treatment considerations in dentistry," Japanese Dental Science Review, vol. 50, no. 1, pp. 1-8, 2014.

[8] P. A. Lotke, "Ossification of the Achilles tendon. Report of seven cases," The Journal of Bone \& Joint Surgery, vol. 52, no. 1, pp. 157-160, 1970.

[9] M. A. Proctor and C. H. Epps Jr., "Post traumatic ossification of the Achilles tendon," Journal of the National Medical Association, vol. 68, no. 5, pp. 368-390, 1976.
[10] R. M. Cohn, R. Schwarzkopf, and F. Jaffe, "Heterotopic ossification after total hip arthroplasty," American Journal of Orthopedics, vol. 40, no. 11, pp. E232-E235, 2011.

[11] V. I. Sakellariou, E. Grigoriou, A. F. Mavrogenis, P. N. Soucacos, and P. J. Papagelopoulos, "Heterotopic ossification following traumatic brain injury and spinal cord injury: insight into the etiology and pathophysiology," Journal of Musculoskeletal \& Neuronal Interactions, vol. 12, no. 4, pp. 230-240, 2012.

[12] H. C. Chen, J. Y. Yang, S. S. Chuang, C. Y. Huang, and S. Y. Yang, "Heterotopic ossification in burns: our experience and literature reviews," Burns, vol. 35, no. 6, pp. 857-862, 2009.

[13] N. Joshi, E. Diaz, and J. Massons, "Achilles tendon ossification," Acta Orthopaedica Belgica, vol. 60, no. 4, pp. 432433, 1994.

[14] S. Agarwal, S. J. Loder, D. Cholok et al., "Scleraxis-lineage cells contribute to ectopic bone formation in muscle and tendon," Stem Cells, vol. 35, no. 3, pp. 705-710, 2017.

[15] J. Chalmers, D. H. Gray, and J. Rush, "Observations on the induction of bone in soft tissues," Journal of Bone and Joint Surgery, vol. 57-B, no. 1, pp. 36-45, 1975.

[16] A. Marusic, V. Katavic, D. Grcevic, and I. K. Lukic, "Genetic variability of new bone induction in mice," Bone, vol. 25, no. 1, pp. 25-32, 1999.

[17] K. Dua and J. M. Barsi, "Heterotopic ossification of the peroneus brevis tendon in a pediatric patient," The Journal of Foot and Ankle Surgery, vol. 56, no. 6, pp. 1316-1319, 2017.

[18] G. Klammer, L. D. Iselin, H. M. Bonel, and M. Weber, "Calcific tendinitis of the peroneus longus: case report," Foot \& Ankle International, vol. 32, no. 6, pp. 638-640, 2011.

[19] M. Trono, S. Tueche, C. Quintart, M. Libotte, and J. Baillon, "Peroneus quartus muscle: a case report and review of the literature," Foot \& Ankle International, vol. 20, no. 10, pp. 659-662, 1999.

[20] F. H. Gannon, B. A. Valentine, E. M. Shore, M. A. Zasloff, and F. S. Kaplan, "Acute lymphocytic infiltration in an extremely early lesion of fibrodysplasia ossificans progressiva," Clinical Orthopaedics and Related Research, vol. 346, pp. 19???25$19 ? ? ? 25,1998$. 


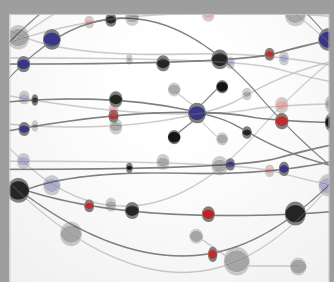

The Scientific World Journal
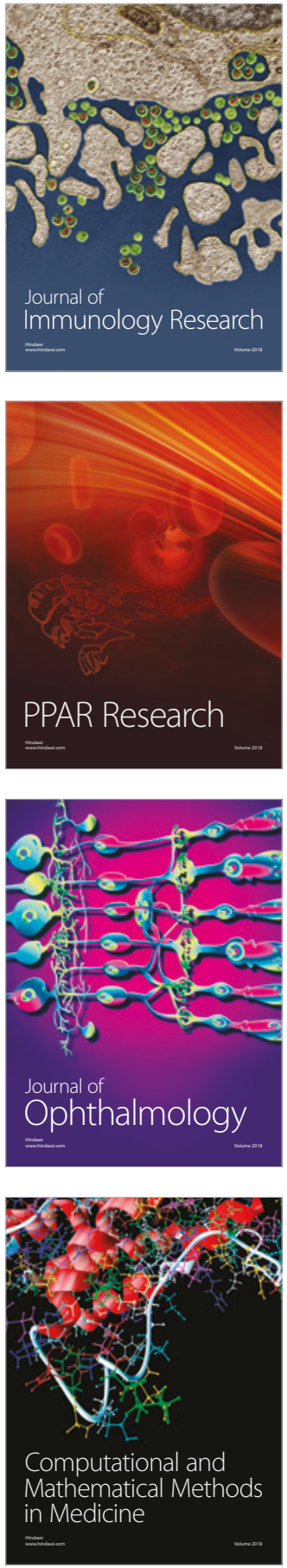

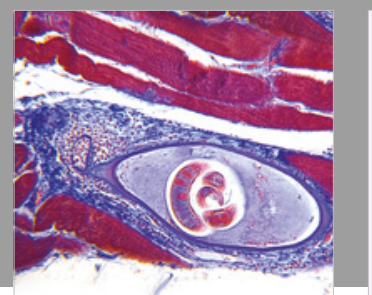

Gastroenterology Research and Practice

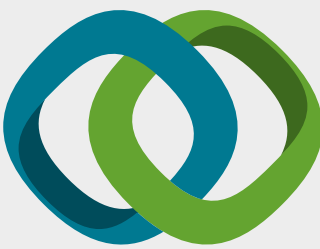

\section{Hindawi}

Submit your manuscripts at

www.hindawi.com
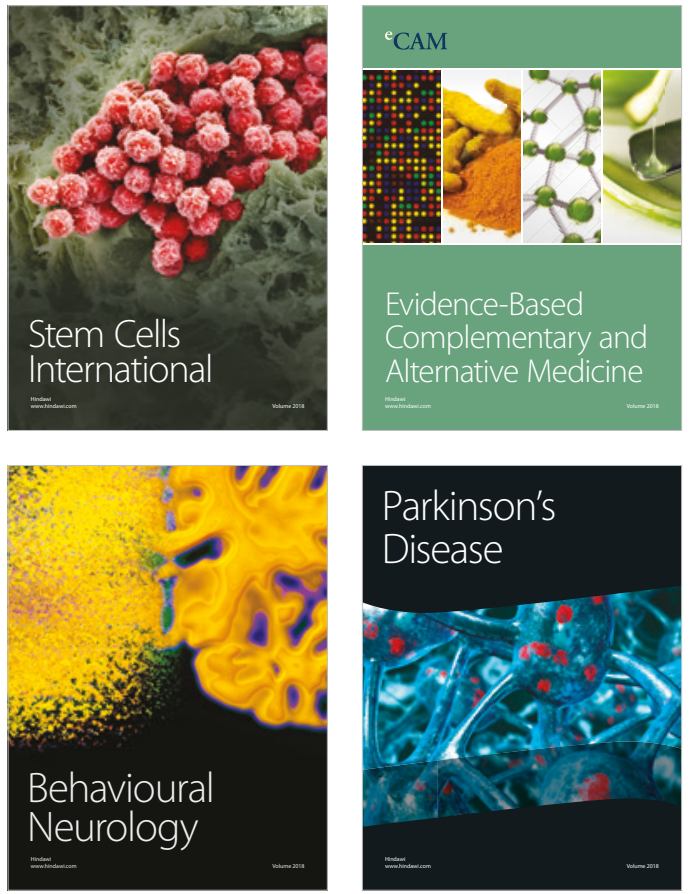

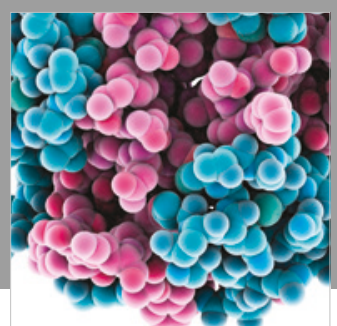

ournal of

Diabetes Research

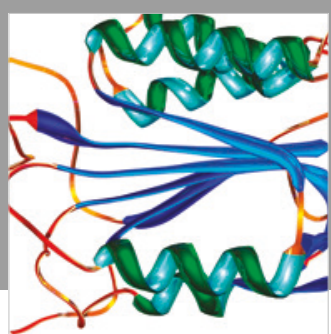

Disease Markers
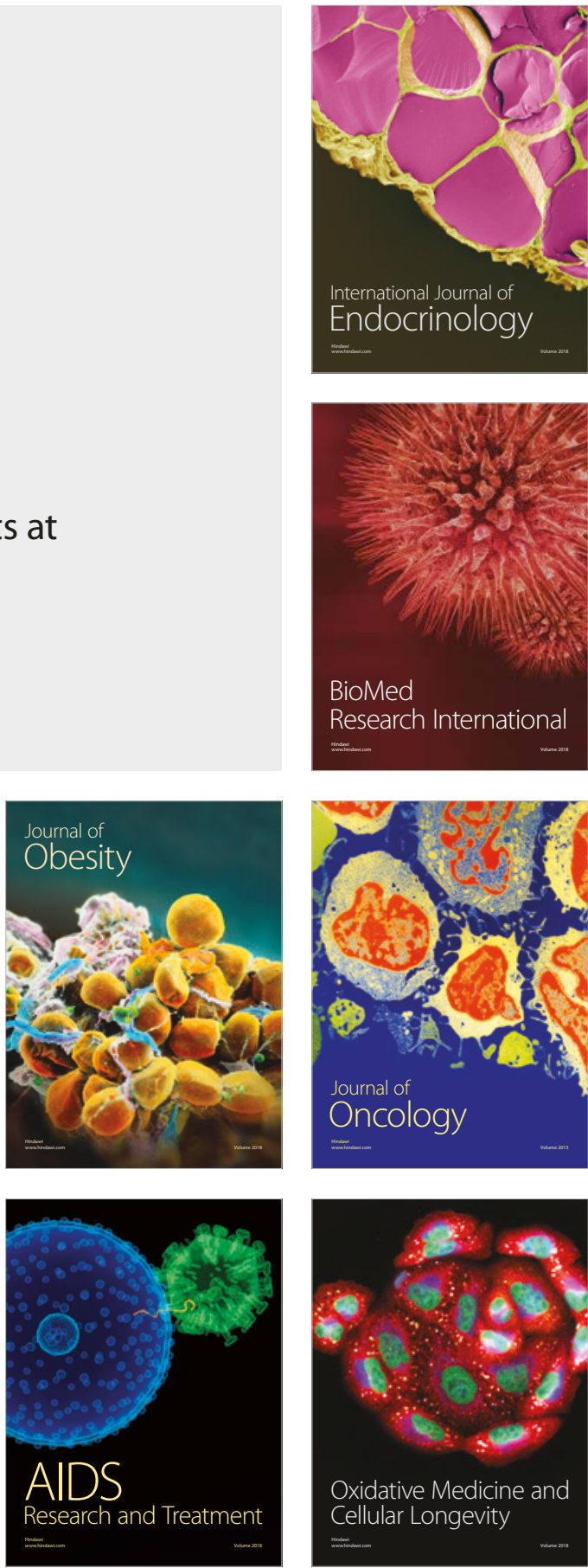